\title{
A SIMULATION-BASED APPROACH FOR ESTIMATING THE COMMERCIAL CAPACITY OF RAILWAYS
}

\author{
Giuseppe Confessore \\ Giacomo Liotta \\ Strada della Neve \\ Via Salaria Km. 29,300 \\ Institute of Industrial Technologies \\ and Automation \\ National Research Council of Italy \\ (ITIA - CNR) \\ Montelibretti (Rome), 00010, ITALY
}

\author{
Patrizia Cicini \\ Francesco Rondinone \\ Piazza della Croce Rossa, 1 \\ Rete Ferroviaria Italiana S.p.A. \\ Rome, 00161, ITALY
}

\author{
Paolo De Luca \\ Via Nizza, 45 \\ ACT Solutions S.r.l. \\ Analytics and Control Technology \\ Rome, 00198, ITALY
}

\begin{abstract}
Rail transport is expected to play a remarkable role for a sustainable mobility in Europe. This paper presents an approach for estimating the commercial capacity of railways. The commercial capacity is intended as the number of possible paths in a defined time window on a rail line, or part of it, considering a fixed path mix, with market-oriented quality. The capacity management is one of the most important tasks of railway Infrastructure Managers. The proposed simulation-based approach relies on the use of an optimizer and a simulator. The study has been developed for the rail line Verona-Brennero, located in the Italian part of the European Corridor Hamburg-Napoli. Computational results allowed to estimate the commercial capacity differences between the whole line and three important line sections within it. Other computational experiments showed the relevant estimated increase in commercial capacity that a reduction in time spacing between trains could imply.
\end{abstract}

\section{INTRODUCTION}

Rail transport is expected to play a remarkable role for a sustainable mobility in Europe. The current situation highlights a strong orientation to the enhancement of rail infrastructures throughout Europe via high-speed corridors that are expected to relieve congestion in road networks while reducing fuel consumption as well as environmental and social impacts of road transport. Moreover, several investments programs concern technologically advanced rolling stock (e.g., high-speed trains for both freight and passengers) and harmonized technical solutions for interoperability and inter-modality.

In the European Union with 25 countries considered (EU-25), the final energy consumption increased between 1990 and 2004 by $12.6 \%$ with a dominant role of the transport sector which revealed an increase of $29 \%$ (EUROSTAT 2006). In the EU the final energy consumption of transport accounted for about 30\% in 2004. Within this share, road transport accounted for about $83 \%$ and aviation for about $13 \%$ (European Commission - EUROSTAT 2007); the share of rail transport was then significantly lower than the mentioned transport modes. Rail transport in Europe mainly exploits electric power. About 80\% of the European rail fleet is powered by electricity while the remaining $20 \%$ is powered by diesel fuel (Community of European Railway and Infrastructure Companies and International Union of Railways 2009). In 2004 electricity consumption for transport in the EU-25 (essentially used for railways, subways, tramways) accounted for $2.7 \%$ with an increase between 1990 and 2004 by $20 \%$, from $59085 \mathrm{GWh}$ to $70861 \mathrm{GWh}$ (European Commission - EUROSTAT 2006).

This data significantly shows the great contribution that a shift towards a massive use of the rail mode for both freight and passengers mobility could bring to:

- The reduction in final energy demand and fossil fuels dependency currently generated by road transport.

- The minimization of environmental and social impacts of transport.

The latter issues concern air pollution, carbon dioxide and other greenhouse gas emissions, noise, accidents and transport safety, network congestion that contribute to the external costs of transport. In 2005, transport sector was responsible for the $27 \%$ of carbon dioxide emissions in the EU-27. The related shares were distributed as listed: road transport $72 \%$, aviation $12 \%$, sea and inland waterways 15\%, railways $1.6 \%$ (Community of European Railway and Infrastructure Companies and In- 
ternational Union of Railways 2009). Therefore, from the environmental and social viewpoints, rail transport can be considered safer and environmentally friendlier than other transport modes. Diverse research topics have been fixed in Europe for the development of a sustainable rail transport. Among these, some aims explicitly address environmental issues under several perspectives, e.g., reduction in train weights and in noise emissions, hazardous materials issues, better traffic management and train control for improved traffic flows. The maximization of the rail network capacity in commercial terms leads to a higher availability of paths for capturing transport shares of other modes that currently have a more critical influence on environment and society (e.g., road transport). Therefore, the managers of European rail infrastructures have been encouraged for defining international corridors, e.g., for freight transport, in order to extend the scope of their initiatives and to set common objectives.

European policy directives foresee that in each country the Infrastructure Manager (IM) must be separated from the Railway Undertakings (RU) (Council of the European Communities 1991). The IM is focused on maintaining a safe, secure and reliable railway infrastructure, on planning and control of train traffic. The RU operate for the provision of rolling stock and transport services. This organizational configuration has to assure the access to the common network infrastructures requested by several RU on equal terms.

The capacity management is one of the most important tasks of the IM. Before thinking about the investments on new lines or heavy measurements on the infrastructure, it is necessary to increase the existing capacity by optimizing the timetable, or by adopting ad hoc measurements in the operation, possibly with the support of computer-based decision system.

The capacity as such does not exist, as reported in the UIC Code 406 (Union Internationale de Chemins de Fer 2004). We always need to specify the kind of capacity we are talking about. The Italian IM assumed as internal coded definitions those reported in UIC Code 406; they are:

- Theoretical capacity, the maximum number of trains that can be calculated by defining ideal circumstances (i.e., homogeneous traffic and shortest possible spacing for all trains).

- Commercial capacity, (capacity in the UIC Code 406) smaller than the theoretical capacity because it considers more realistic elements such as train mix, priorities, buffer times, maintenance time windows, etc.; it can be defined as the number of possible paths in a defined time window on a rail line, or part of it, considering a fixed path mix, with market-oriented quality. The path is the possibility to run on a railnet section between two stations in a fixed time window.

- Usable capacity, the difference between commercial capacity and traffic demand.

Similar definitions can be found in the technical literature (see Abril et al. 2008).

This work is focused on the assessment of the commercial capacity of railways. The paper presents a methodology and a simulation-based prototype for estimating the commercial capacity of rail lines. An algorithm and a simulation model have been designed and developed. The adopted approach implements a standard technique officially issued, in the UIC Code 406, by the International Union of Railways, i.e., the Union Internationale de Chemins de Fer (UIC). UIC is the technical and normative body consisting of the representatives of the most important Railway Companies.

The proposed approach has been successfully tested by using the real data of a line of the Italian part of the European Corridor Hamburg-Napoli, located in the north of Italy that connects the city of Verona with the Brennero, corresponding to the border between Italy and Austria.

Literature review revealed interesting works that, although addressing issues strictly related to the railway planning and control, do not exactly fit with the aims and the problem tackled in this work.

The remainder of the paper is organized as follows: Section 2 presents the state of the art concerning the methods and tools for the assessment of the commercial capacity while concurrently presenting related findings and literature. The problem faced is described in Section 3. Section 4 presents methodology, solution approach and exploited tools. Computational results are presented and discussed in Section 5. Conclusions follow.

\section{STATE OF THE ART}

Technical literature (see Abril et al. 2008) presents the set of methods for estimating the capacity of a rail line by identifying three subsets:

1. Analytical methods.

2. Optimization methods.

3. Simulation methods. 


\section{Confessore, Liotta, Cicini, Rondinone and De Luca}

In Abril et al. (2008) a review of these methods is presented. The authors distinguish among the three mentioned subsets of methods. Abril et al. (2008) argue that analytical methods are mainly devoted to identify preliminary solutions and reference values by means of mathematical formulae and algebraic expressions. Nevertheless, according to the cited authors, they represent good starting points for identifying relevant bottlenecks and constraints in railway line capacity computation and for beginning optimization processes. The results depend on the adopted method with the consequence that they can have more or less accuracy. Italian Rail Infrastructure Manager adopts an own developed net model and utilizes it to manage path requests in the operational phase of train circulation. Optimization methods mainly aim at obtaining optimal saturated timetables by using mathematical programming techniques and graph representations (Abril et al. 2008). Typical applications are used for solving scheduling problems under several constraints. Abril et al. (2008) include the UIC Compression Method, i.e., UIC Code 406, in the optimization methods; saturation is considered as a particular optimization method. UIC elaborated the Code 406 with the support of the main European Rail Infrastructure Managers (including the Italian one) to codify the compression methods. The third subset presented in Abril et al. (2008) concerns simulation methods that are developed for testing solutions of optimization methods or validate timetables.

According to Abril et al. (2008), the three subsets correspond to three levels for obtaining, respectively: preliminary solutions for capacity assessment, desired train schedules and then their validation. The same authors conclude that current trends envisage integrated approaches that embed analytical, optimization and simulation methods.

Literature review concerning analytical and optimization methods confirm the major findings above mentioned. The cited papers concern diverse applications of analytical and optimization methods in railway management.

Caprara et. al. (2006) investigate the train timetabling problem and develop a Langragian heuristic algorithm for solving it. The problem faced takes into account additional constraints deriving from real world instances such as manual block signaling, station capacities, prescribed timetables for a subset of trains, maintenance operations. Abril et al. (2008) present a computer-based tool (the MOM system) that encompasses analytical and empirical methods in a railway capacity module. The MOM system exploits an optimization module for obtaining compacted timetables, saturated timetables, and carrying out other capacity assessments. The railway capacity module can support managers in evaluating the capacity of railway networks and in deciding the adaptation of the railway infrastructure to traffic needs. Delorme, Gandibleux, and Rodriguez (2009) investigate the stability of railway timetables by using an optimization model while taking into account delay propagation. The software tool developed in their project allows also to evaluate infrastructure modifications. Fransoo and Bertrand (2000) describe a model for identifying potential cases for introducing infrastructure extensions and evaluating the related implementation alternatives. These extensions correspond to passing constructions, i.e., partial double track on a line, that in the model are evaluated without providing detailed timetables. The proposed model allows to estimate the capacity of the extended infrastructure. De Kort, Heidergott, and Ayhan (2003) face the capacity assessment problem while considering a time window of 60 minutes and using a probabilistic approach that does not consider particular timetables. The authors present the related optimization problem and the solution approach based on an algorithm coded in $\mathrm{C}++$. The case study of the Netherlands portion of an high-speed railway is presented. D'Ariano, Pacciarelli, and Pranzo (2008) investigate the use of flexible arrival/departure times and advanced scheduling algorithms for conflict resolution on a bottleneck area of the Dutch railway network. A flexible timetable is intended as a less detailed timetable with more control decisions left to the dispatcher. The authors make use of several conflict resolution algorithms. Dorfman and Medanic (2004) investigate the train scheduling problem over a network. Their approach is based on the concept of a Travel Advanced Strategy, i.e., a service discipline, and it is developed by using a discrete event model of railway traffic. The used greedy approach generates suboptimal schedules close to the optimal ones in practical situations. Within the model a capacity check is performed. Energy efficient schedules can be generated by considering train velocities and time feasibility. Ghoseiri et al. (2004) present a multi-objective optimization model for the passenger train scheduling problem. The considered railroad network includes single and multiple tracks, and multiple platforms with different train capacities. In Rondinone (2009) an analysis and evaluation of railways commercial capacity have been outlined and developed.

Literature review concerning simulation for railway management highlights several applications and approaches. Luethi, Medeossi, and Nash (2009) propose an integrated real-time rescheduling system that relies on an algorithm. The results are tested through simulation. The system allows to observe that the capacity can be increased and knock-on delays can be reduced. Weits (1998) makes effectively use of an object-oriented modeling approach and simulation for the railway traffic control. Azadeh, Ghaderi, and Izadbakhsh (2008) developed an integrated approach consisting of computer simulation, Data Envelopment Analysis and Analytical Hierarchy Process. The use of the simulation model aims at increasing reliability of the timetable of passenger trains, decreasing average traverse time of both cargo and passenger trains. Hallowell and Harker (1998) consider the application of the analytical Line Delay Model and a method for calculating likely train arrival and departure times. In their work Monte Carlo simulations are conducted. Their approach is intended to adjust the targets, i.e., schedules, for a rail line. In Middelkoop and Bouwman (2001) a simulation environment (Simone) for generating and analyzing complex and large scale train networks is presented. The aims of Simone are to support the robustness assessment of the 
timetables, analyze network stability, delays, bottlenecks of the network, delay related to different layouts of the railway infrastructure, improve timetables. Krueger (1999) presents a Parametric Capacity Model for measuring the capacity of individual subdivisions of a rail network. The capacity is meant as theoretical, practical, used \& available track capacity. The decision support process implies the use of the parametric model which considers plant, traffic, operating parameters and the use of event-based simulation. Kanacilo and Verbraeck (2006) developed a service oriented simulation architecture in order to model rail infrastructures. In particular object-oriented simulation libraries have been created for modeling physical, control, statistics, input and output processing aspects through classes corresponding to the mentioned simulation service types. The purpose is to estimate in detail the rail infrastructure capacity while supporting the control design of the infrastructure. In Barber et al. (2007) several simulation-based systems for railway management are presented with their characteristics.

With respect to the numerous issues and methods presented, the methodological approach addressed in our work is focused on high level planning of commercial capacity in order to obtain reliable estimates for assessing and possibly extending the commercial offer of paths by IMs to RUs. Operational management in terms of scheduling decisions, timetables and other real time planning and control decisions are out of the scope of this work. In our simulation-based approach we make use of a general optimization method, i.e. the Compression Method described in the UIC Code 406 (2004), implemented by an $a d$ hoc algorithm. We then test and validate the robustness of the solutions obtained through discrete event simulation. Commercial capacity estimates and their stochastic deviations are generated.

The UIC Code 406 method is commonly utilized by the Italian IM to support strategic decisions that are based on mediumlong term infrastructural scenarios together with national and international traffic forecast. The method is simple and useful to calculate rail lines commercial capacity, and, consequently, to determine the bottlenecks in the different future scenarios. It is also recognized as valid instrument in the international technical working groups in which the Italian IM is represented. In the last two years it has been utilized in the Working Groups of Freight European ERTMS Corridor A (Rotterdam-Genova) and Corridor B (Hamburg-Napoli).

\section{PROBLEM DESCRIPTION}

The problem faced is to maximize the commercial capacity of rail lines while taking into consideration the following constraints and parameters:

- Line type (single or double track).

- Stations.

- Signaling conditions.

- Maintenance time windows.

- Traffic mix of planned timetable.

- Overtaking between trains.

- Crossing traffic conditions.

Constraints and parameters represent the conditions to be satisfied by the model. The line type (single or double track) defines whether the traffic along a direction depends or not on the traffic in the opposite direction. In case of traffic independency the compression has less constraints to be respected. Stations are considered as points; this is a problem simplification that avoids to take into account what happens within station. The method works well on a line and not in a station. Signaling conditions impose the minimum time interval between two following trains to be respected for safety (i.e., time spacing). The more advanced are the signaling technologies, the shorter is the minimum time interval between two following trains. Maintenance time window reduces the availability of line commercial capacity because in that time window it cannot be any traffic on the rail. The more maintenance operations last, the minor is the line commercial capacity. Overtaking between trains is a measure utilized to optimize the commercial capacity. The slowest trains are overtaken by the fastest ones. In the opposite case the commercial capacity is strongly reduced. The commercial capacity depends on the distance of the stations where it is possible to operate an overtaking. Concerning the crossing traffic conditions, there are cases in which two rail lines cross each other. The crossing traffic flow is an obstacle to the traffic flow on the analyzed line. The effect can be a strong reduction in commercial capacity.

The assessment of the commercial capacity has to meet the mentioned requirements and constraints, taken into account in the "Compression Method" defined in the UIC Code 406. The selected case study is the Italian rail line Verona-Brennero.

\section{METHODOLOGY AND SOLUTION APPROACH}

The methodological approach is based on the integrated use of optimization and simulation. Literature highlights several approaches that combine the use of simulation and optimization techniques (e.g., Simulation Optimization, simulation with em- 
bedded optimization). In April et al. (2004) a tutorial on real applications is presented. In the study herein presented the simulation is exploited for testing and validating the robustness of an optimization process. Nevertheless, scenario analyses can be conducted by modifying input, parameters and structure of the simulation model.

The aim of the work is to perform high level planning of commercial capacity in order to obtain reliable estimates for assessing and possibly extending the commercial offer of paths by IMs to RUs. In Figure 1, the estimation process of the commercial capacity is represented by highlighting input and output of both the phases. The optimization phase foresees the solution of a simplified version of a job-shop scheduling problem with no-wait constraints. The solution is obtained through a constructive algorithm that dynamically builds the trains' paths compliant with problem's constraints and parameters.

The simulation phase is devoted to the test of the solutions obtained through the optimizer in terms of robustness. A discrete event simulation of traffic, infrastructure and operations works by mainly producing the same measure types of the optimizer. The outcomes of this phase are paths, commercial capacity estimates and their stochastic deviations, and other relevant time and utilization performance indicators useful for decision makers. The added-value of the simulation phase is the possibility to include in the compression process stochastic elements (e.g., traffic perturbations and propagations), to add several output data to the assessment process related to performance levels, to provide a more detailed descriptions and features of the infrastructure and trains that it is not possible to consider in the optimization phase.

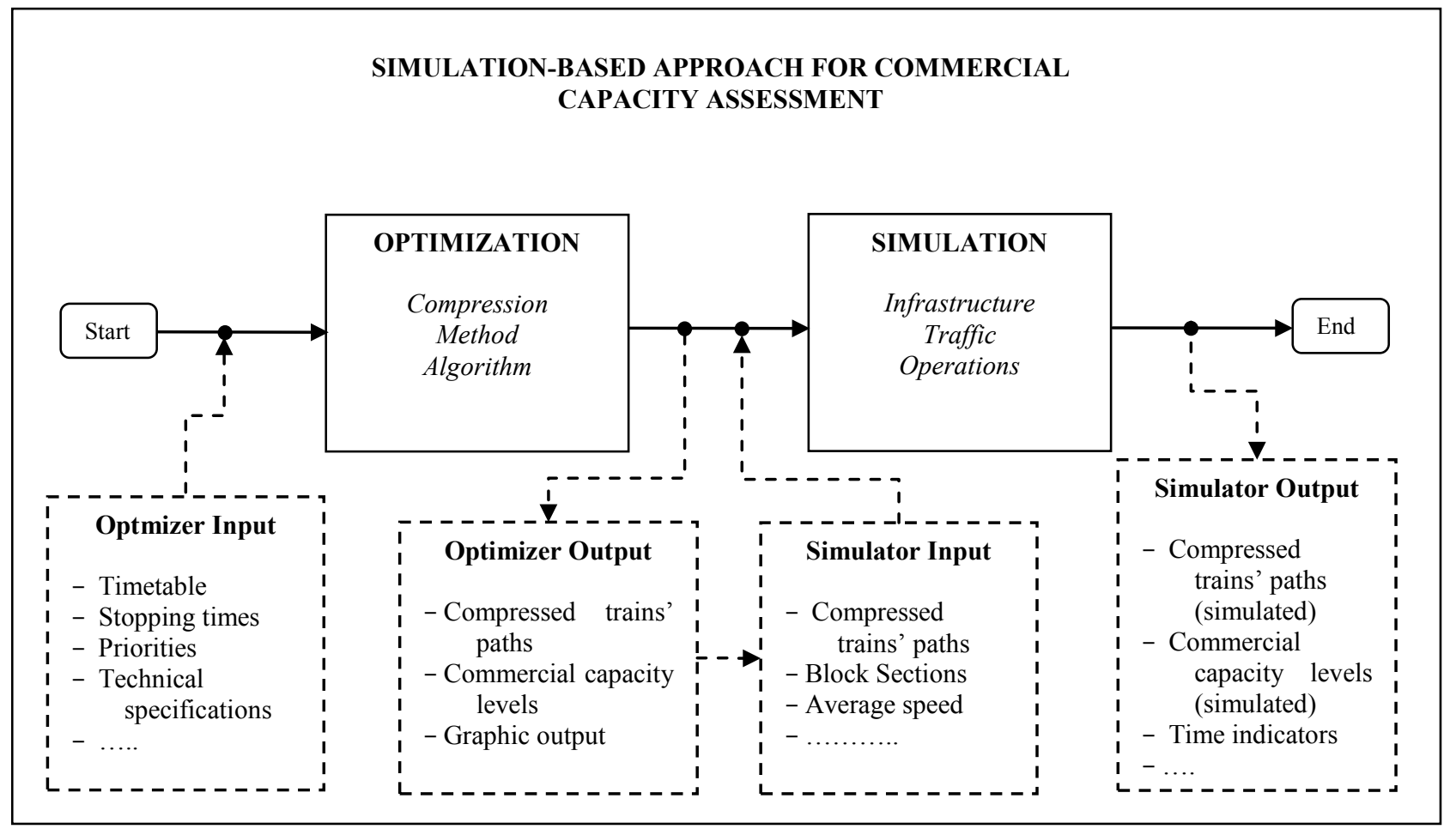

Figure 1: Simulation-based approach

\subsection{Compression Method and solution algorithm}

A compression process allows to estimate the commercial capacity of a rail line. The Compression Method reported in the UIC Code 406 addresses specific technical issues that constitute guidelines, parameters and constraints to be considered in a compression decisional process. The method compacts the trains' paths while considering a fixed timetable. The quality of the obtained results depends on the satisfaction of its constraints and parameters.

Since the Compression Method is a general procedure that provides guidelines for capacity assessment while considering technical specifications, in this study an algorithm that is compliant with the general compression process of the UIC Code 406 has been designed and developed.

With regard to Figure 1, the designed algorithm for compression is exploited in the optimization phase. The problem described in Section 3 has been generalized, for the purposes of our work, through a simplification of an optimization problem known in the literature as a job-shop scheduling problem with no-wait constraints (see for example also Mascis and Pacciarelli 2002). The solution algorithm that has been developed can be classified as a constructive search algorithm. It dynamical- 
ly builds the solution by recursively checking step by step the solution in progress. The algorithm minimizes the departure times of trains in order to calculate the commercial capacity.

The algorithm receives as input the following items:

- Timetable for all the stations considered that includes arrival, stop and departure times.

- Technical specifications given by regulations in terms of constraints and parameters.

The technical specifications are related to line type, line sections, stations, signaling, maintenance time windows, traffic mix of planned timetable, overtaking between trains, spacing, crossing traffic conditions.

A step of the algorithm is a calculation phase that considers a pair of adjacent stations in the rail line sequence. Concerning two consecutive steps, the arrival station of the former step correspond to the departure station of the latter one.

In a generic step $n$, the algorithm calculates for each train the minimum feasible departure time from the first station of the considered pair. This departure time is computed by taking into account the arrival time in the second station of the step $n-1$ and the possible stopping time.

Some factors, e.g., train priorities, different train speeds, additional trains departing from the first station of the step $n$, can cause a difference between the departure time of a train from the first station of the step $n$ and the sum of $(i)$ the arrival time in the second station of the step $n-1$ and (ii) the possible stop time. If this event occurs, then the path of a train (i.e., the set of the arrival and departure times in all the considered stations) and the paths of the trains following it are recalculated in order to make feasible the entire solution computed up to the step $n$.

The algorithm provides the following output:

- Total compression time, i.e., the time allocated for trains' paths.

- Commercial capacity for the entire line and for each line section.

- Graphic representations.

\subsection{Simulation model}

The simulation phase has been performed by developing a discrete event simulation model. The model has been exploited for verification and validation purposes. In fact, the solutions provided by the optimization phase in terms of compression time and commercial capacity have been tested by the simulator while also including a traffic perturbation factor due to the finite capacity of line, block sections and trains' speeds. In particular the aim is to evaluate the deviations of commercial capacity between the optimizer and the simulator. In fact, in the optimization phase it is not possible to include some elements of the simulation model and the time spacing between trains is fixed. In the simulation model the spacing between trains is defined by the block sections.

The input of the simulation model are:

- Arrival, stop and departure times of the trains.

- The average speeds between stations.

- The types of trains and their features.

- Technical specifications.

With respect to the optimizer, the simulator additionally considers the block sections and the related distances. The discrete event simulation model reproduces the entire traffic and its characteristics and the characteristics of the block sections.

In particular the movements of each train throughout the line are simulated. The departing trains within a 24 hours time interval are considered. The rail line is modeled through a sequence of block sections with the related distances. The trains pass through the line and they are modeled while including their characteristics (e.g., freight or passenger train, speed, etc.). The train priority constraints are satisfied, thus the possible overtaking is simulated. The simulation model must satisfy the safety constraints (e.g., time spacing between trains) in order to make feasible all the arrival and departure times between each block section. The model verification and validation have been carried out by means of graphic animation and comparisons between the obtained output of particular scenarios purposively built about which the correct results were $a$ priori known. The simulation terminating condition is the arrival time of the last train to the last station of the line.

The output of the simulation model are:

- Total compression time for each pair of stations 
- Commercial capacity

- Flowtime for each train.

- Waiting time for traffic in block sections.

- Utilization degree of block sections and stations.

\subsection{Tools}

The algorithm has been developed through Visual Basic 6.0 programming language. It automatically reads and writes input/output data by interacting with Microsoft Access databases. The implemented algorithm builds graphic charts of trains' paths and capacity levels into Microsoft Excel files. The graphic output have been exploited for the debug of the algorithm code. The graphic outputs are dynamically built and visually represent all the necessary characteristics of the traffic (e.g., constraints of technical specifications, arrival, stops, departures, overtaking, priorities, etc.). In Figure 2 a generic graphic output between the origin and a $i$-th station is presented.

The discrete event simulation model has been developed in the Arena 12.0 (Rockwell Software) simulation environment. The simulator reads and writes input/output data from/to Microsoft Access databases.

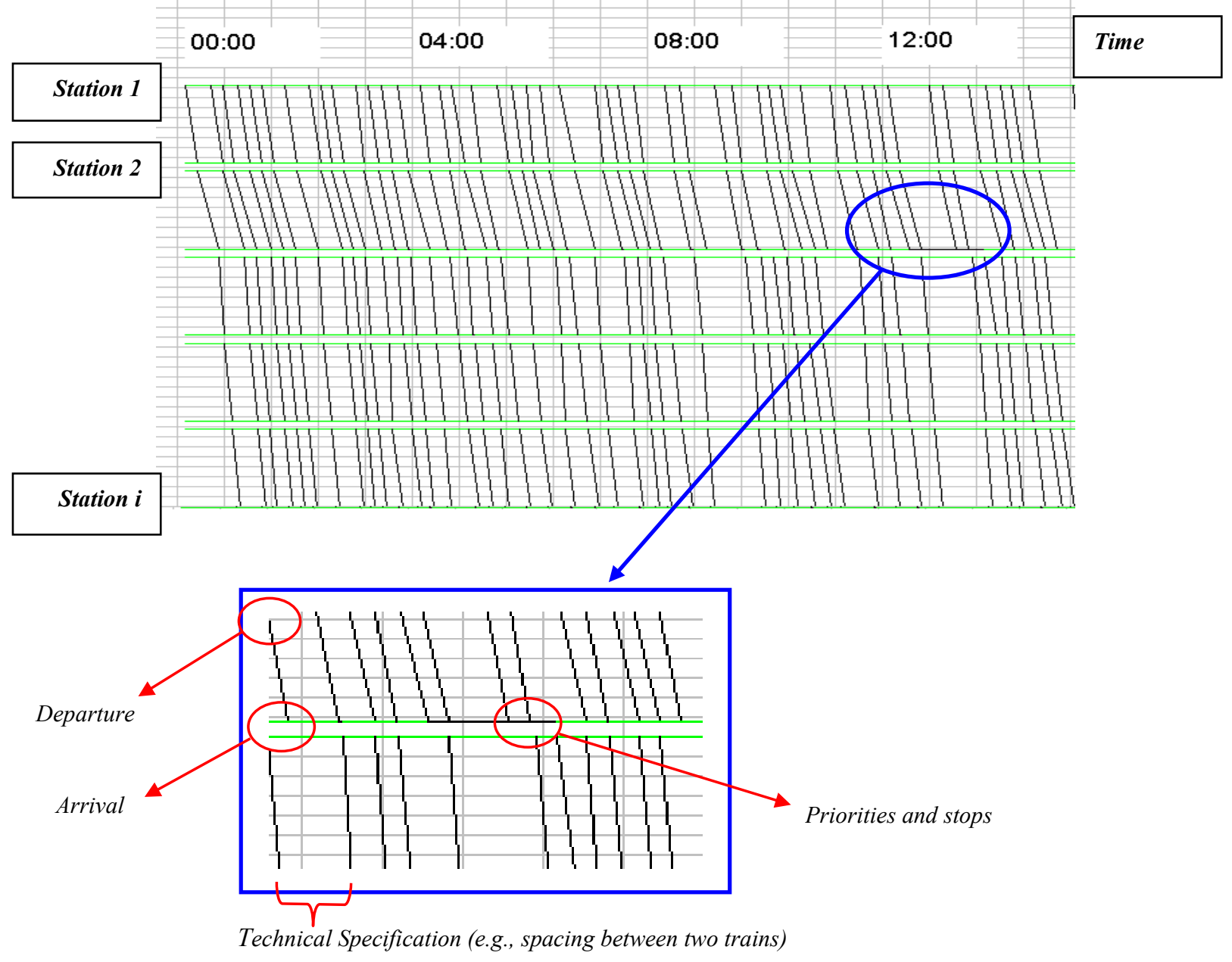

Figure 2: Graphical output of trains' paths

\section{COMPUTATIONAL RESULTS AND DISCUSSION}

The experimental phase of the study aims at observing and estimating the commercial capacity from two main standpoints:

1. Commercial capacity of the whole line and of its relevant parts by using a standard time spacing between trains. 
2. Trends of the commercial capacity throughout the line by reducing the minimum time spacing between trains.

The computational results have been obtained by the optimizer and then by the simulator. The deviation among the different experiments is presented. The commercial capacity is measured in terms of number of trains (i.e., the total number of trains that can depart throughout the line during a 24 hours time interval). The results are accordingly presented.

In the first assessment process three relevant line sections are defined. In this experiment the time spacing is equal to 6 minutes. In Figure 3 it is possible to observe the variability of the commercial capacity by comparing the whole line commercial capacity and the related levels of the line sections (in Figure 3 named macro line sections). The commercial capacity of the whole line is lower than the commercial capacity separately observed in the line sections identified. The difference among the line commercial capacity and the related capacities of the defined line sections is between $29 \%$ and $49 \%$. These results are aligned with the expectations because the global commercial capacity of the line concurrently considers a number of train typologies and more constraints related to the number of line sections that compose itself. In fact, the whole line consists of line sections. The commercial capacity calculation of the line takes into account the constraints related to previous and successive line sections within it. Conversely, the calculation of the commercial capacity of a single line section does not consider the constraints related to the previous and successive ones and, generally, traffic mix, number of trains, infrastructure and signaling conditions do not vary (Union Internationale de Chemins de Fer 2004). The results in Figure 3 are obtained by the optimizer. The deviation between the optimizer and simulator results for this computational experiment is comprised in the interval $0.05-1 \%$.

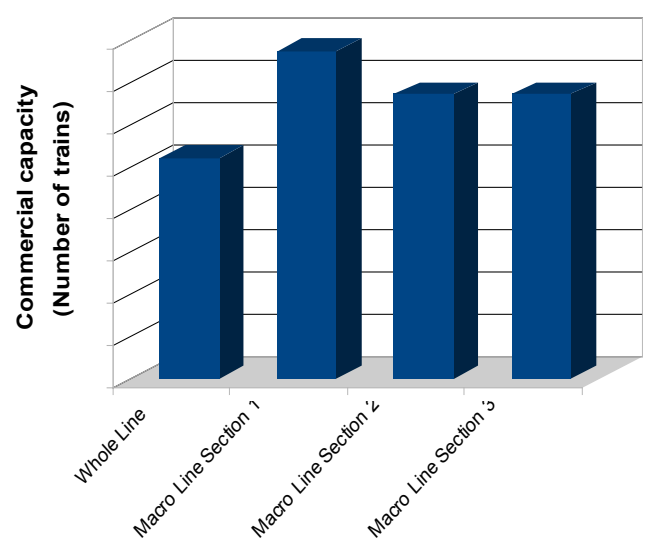

Figure 3: Commercial capacity of the whole line and relevant line sections

The second assessment process is focused on the observation of the commercial capacity trends, throughout the whole line, determined by the optimizer by progressively reducing the fixed time spacing between trains by 1 minute. Six scenarios have been defined. The trends presented in Figure 4 are related to the computational results of the scenarios.

The commercial capacity can vary along the line, depending generally on the timetable, the train mix and on infrastructure characteristics and equipment. The capacity steps, found along this line, are due to different timetable and train mix between the sections.

The commercial capacity is expected to increase while the time spacing (Tmin) of the technical specifications is decreasing. The comparison among the trends that represent the two scenarios with a spacing, respectively, equal to 6 and 1 minute, allowed to conclude that the variability of the commercial capacity is approximately equal to $50 \%$.

The commercial capacity has been then estimated through simulation experiments also in this assessment process. In the simulation experiments additional elements are considered with respect to the optimization phase: the speeds and the block sections that compose each line section. 


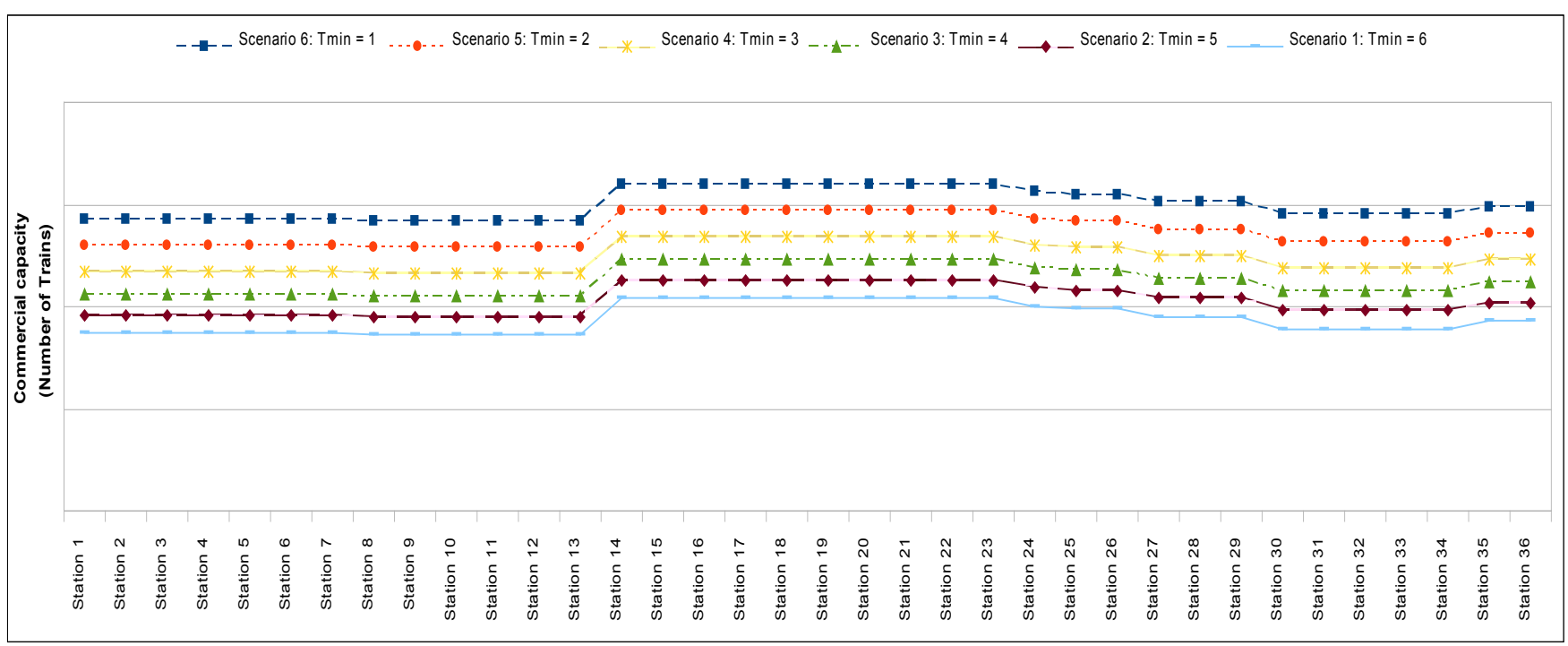

Figure 4: Commercial capacity trends with variation of minimum time spacing

The deviation between optimizer and simulation results are presented in Table 1. The optimizer and the simulator work in an integrated way. The contribution of the simulator can be viewed from a twofold perspective: $(i)$ in terms of evaluation of the quality of the results given by the optimizer and (ii) in terms of improvement of the commercial capacity assessment because the simulation results suggest a slight reduction in the estimates as reported in Table 1. The low deviations allow to conclude that a very good quality of the algorithm in the optimization phase has been obtained. The additional elements included in the simulation models highlight that a poor estimated reduction in commercial capacity should be considered for each scenario.

Table 1: Reductions in commercial capacity results of the simulator w.r.t. the optimizer

\begin{tabular}{|l|c|c|c|c|c|c|}
\hline $\begin{array}{c}\text { Reduction between simulator and optimizer } \\
\text { commercial capacity results }\end{array}$ & \multicolumn{5}{|c|}{ Scenarios of time spacing (Tmin) between trains } \\
\cline { 2 - 7 } & $\mathbf{6}$ min. & $\mathbf{5}$ min. & $\mathbf{4}$ min. & $\mathbf{3}$ min. & $\mathbf{2}$ min. & $\mathbf{1}$ min. \\
\hline Minimum reduction & $0,05 \%$ & $0,06 \%$ & $0,06 \%$ & $0,07 \%$ & $0,21 \%$ & $0,23 \%$ \\
\hline Average reduction & $0,30 \%$ & $0,33 \%$ & $0,36 \%$ & $0,40 \%$ & $0,58 \%$ & $0,81 \%$ \\
\hline Maximum reduction & $0,73 \%$ & $0,80 \%$ & $0,89 \%$ & $0,98 \%$ & $1,28 \%$ & $1,66 \%$ \\
\hline
\end{tabular}

\section{CONCLUSIONS}

The work herein presented is focused on the assessment of the commercial capacity of railways. The adopted approach makes use of optimization and simulation with the aim of obtaining the solutions of an optimization problem and then testing their robustness via a simulator. The proposed approach aims at estimating the commercial capacity of rail lines since in Europe the rail transport is expected to notably increase its share. The reduction in environmental, social impacts and energy consumption related to transport are at the basis of an expected and encouraged shift of passengers and freight mobility from other modes to the rail mode. The simulation-based approach developed in this study has been tested through the data of the important rail line Verona-Brennero which is characterized by remarkable shares of both freight and passengers flows.

The computational results related to the commercial capacity, although confirming some main expectations about the factors that impact on its calculation, allowed to quantify specific elements and aspects. In particular, it has been estimated that in the rail line under consideration the difference between the commercial capacity of the whole line and the relevant line sections, that have been identified over it, is comprised in the interval $29 \%-49 \%$. Other computational experiments have been devoted to the evaluation of trends of the commercial capacity throughout the whole line by progressively reducing the time spacing between trains. By comparing the results concerning the limits of the used time spacing (from 6 to $1 \mathrm{~min}$.), the variability of the commercial capacity is approximately equal to $50 \%$. The relevance of strengthening the capability for decreasing the time spacing is then a crucial aspect for the commercial capacity development. Simulation experiments carried out for evaluating the robustness of all the mentioned results revealed a poor estimated reduction in commercial capacity, thus a good quality of results obtained in the optimization phase has been highlighted. The developed study emphasizes the importance of utilizing decision support systems based on the use of optimization and simulation models for facing both 
high-level and more operational challenges related to the development and management of rail infrastructures and services, and to the optimization of existing infrastructures.

\section{REFERENCES}

Abril, M., F. Barber, L. Ingolotti, M.A. Salido, P. Tormos, and A. Lova. 2008, An assessment of railway capacity. Transportation Research Part E 44:774-806.

April, J., M. Better, F. Glover, and J. Kelly. 2004, New advances and applications for marrying simulation and optimization. In Proceedings of the 2004 Winter Simulation Conference, ed. R. G. Ingalls, M. D. Rossetti, J. S. Smith, and B. A. Peters, 80-86. Piscataway, New Jersey: Institute of Electrical and Electronics Engineers, Inc.

Azadeh, A., S.F. Ghaderi, and H. Izadbakhsh. 2008, Integration of DEA and AHP with computer simulation for railway system improvement and optimization. Applied Mathematics and Computation 195:775-785.

Barber, F., M. Abril, M.A. Salido, L. Ingolotti, P. Termos, and A. Lova. 2007, Survey of automated systems for railway management. Technical Report DSIC-II/01/07, Department of Computer Systems and Computation, Technical University of Valencia.

Caprara, A., M. Monaci, P. Toth, and P.L. Guida. 2006, A Lagrangian heuristic algorithm for a real-world train timetabling problem. Discrete Applied Mathematics 154:738-753.

Community of European Railway and Infrastructure Companies, International Union of Railways. Krohn, O., M. Ledbury, and H. Schwarz (authors). 2009, Railways and the environment - Building on the railways' environmental strengths. Community of European Railway and Infrastructure Companies, Brussels.

Council of the European Communities. 1991, Council directive of 29 July 1991 on the development of the Community's railways (91/440/EEC). Official Journal of the European Communities No L 237/25.

D'Ariano, A., D. Pacciarelli, and M. Pranzo. 2008, Assessment of flexible timetables in real-time traffic management of a railway bottleneck. Transportation Research Part C 16:232-245.

de Kort, A.F., B. Heidergott, and H. Ayhan. 2003, A probabilistic (max, + ) approach for determining railway infrastructure capacity. European Journal of Operational Research 148:644-661.

Delorme, X., X. Gandibleux, and J. Rodriguez. 2009, Stability evaluation of a railway timetable at station level. European Journal of Operational Research 195: 780-790.

Dorfman, M.J., and J. Medanic. 2004, Scheduling trains on a railway network using a discrete event model of railway traffic. Transportation Research Part B 38:81-98.

European Commission - EUROSTAT. Bosch, J., F.X. Johnson, R. Mertens, N. Roubanis, P. Loesoenen, A. Gikas, and J. Görten (authors). 2007, Panorama of energy - Energy statistics to support EU policies and solutions. Theme: Environment and energy, Collection: Statistical books. Luxembourg: Office for Official Publications of the European Communities.

European Commission - EUROSTAT. 2006, Panorama of the European Union - Gas and electricity market statistics - Data 1990-2006. Theme: Environment and Energy. Luxembourg: Office for Official Publications of the European Communities.

EUROSTAT. Siakkis, Ph., J. Förster, W. Kloek, K. Jordan, C. Heidorn, J. Cabeca, U. Luksch, N. Steinbach, P. Nadine, and J. Hanauer (authors). 2006, Energy, transport and environment indicators - Data 1990-2004. Theme: Transport, Theme: Environment and Energy. Luxembourg: Office for Official Publications of the European Communities.

Fransoo, J.C., and J.W.M. Bertrand. 2000, An aggregate capacity estimation model for the evaluation of railroad passing constructions. Transportation Research Part A 34:35-49.

Ghoseiri, K., F. Szidarovszky, and M.J. Asgharpour. 2004, A multi-objective train scheduling model and solution. Transportation Research Part B 38:927-952.

Hallowell, S.F., and P.T. Harker. 1998, Predicting on-time performance in scheduled railroad operations: methodology and application to train scheduling. Transportation Research Part A 32(4):279-295.

Kanacilo, M.E., and A. Verbraeck. 2006, Simulation services to support the control design of rail infrastructures. In Proceedings of the 2006 Winter Simulation Conference, ed. L. F. Perrone, F. P. Wieland, J. Liu, B. G. Lawson, D. M. Nicol, and R. M. Fujimoto, 1372-1379. Piscataway, New Jersey: Institute of Electrical and Electronics Engineers, Inc.

Krueger, H. 1999, Parametric modeling in rail capacity planning, In Proceedings of the 1999 Winter Simulation Conference, ed. P. A. Farrington, H. B. Nembhard, D. T. Sturrock, and G. W. Evans, 1194-1200. Piscataway, New Jersey: Institute of Electrical and Electronics Engineers, Inc.

Luethi, M., G. Medeossi, and A. Nash 2009, Structure and simulation evaluation of an integrated real-time rescheduling system for railway networks. Networks and Spatial Economics 9:103-121. 
Mascis, A., and D. Pacciarelli. 2002, Job-shop scheduling with blocking and no-wait constraints. European Journal of Operational Research 143: 498-517.

Middelkoop, D., and M. Bouwman. 2001, Simone: large scale train network simulations. In Proceedings of the 2001 Winter Simulation Conference, ed. B. A. Peters, J. S. Smith, D. J. Medeiros, and M. W. Rohrer, 1042-1047. Piscataway, New Jersey: Institute of Electrical and Electronics Engineers, Inc.

Rondinone, F. 2009, Analisi e valutazione della capacità commerciale delle linee ferroviarie. Laurea Specialistica Degree Thesis (in Italian), Faculty of Engineering, Department of Enterprise Engineering, University of Rome Tor Vergata, Rome, Italy.

Union Internationale de Chemins de Fer. 2004, UIC Code 406 - Capacity. 1st Edition. Union Internationale de Chemins de Fer, Paris.

Weits, H. A. G. 1998, Simulation of Railway Traffic Control. International Transactions in Operational Research 5(6):461469.

\section{AUTHOR BIOGRAPHIES}

GIUSEPPE CONFESSORE is graduated in Electronic Engineering from the University of Rome "La Sapienza" (1992) and received the Ph.D. in Management Engineering from the University of Rome "Tor Vergata" in 1998. Since 1999 is the coordinator of the Rome research group of the ITIA-CNR involved in research activities and projects in production and logistics fields by using operations research and management science methodologies. Since 1999 he has taught "Supply Chain and Production Management" in the Master in Business Administration at the University of Rome "Tor Vergata". He also teaches "Integrated Logistics" in the Management Engineering Course at the same university. He belongs to the Board of Experts of the Italian Educational, University and Research Ministry and of the Italian Economic Development Ministry to evaluate industrial research projects financed by public funds. Author of over 100 papers published on international journals and international conference proceedings, his main research interests are in area of supply chain and production management. His email address is $\langle g$. confessoreditia.cnr. it $>$.

GIACOMO LIOTTA is contract researcher in the Rome research group of ITIA-CNR, in the Supply Chain and Production Management field. His research interests include methodologies and engineering applications for designing and managing manufacturing and service systems. He received his Ph.D in Management and Economics Engineering at the University of Rome "Tor Vergata"; he also assisted, as expert, the teaching of Design and Simulation of Service Systems at the same university and he currently assists the teaching of Integrated Logistics. His educational background includes an MBA and a M.Sc. in Management Engineering from the University of Rome "Tor Vergata". He was involved in national and European co-funded projects. He is author and co-author of about 15 papers published onto international conference proceedings, reviews and books. His main research interests concern the area of supply chain and production management and product lifecycle management. His e-mail address is $<$ g. liotta@itia.cnr.it>.

PATRIZIA CICINI is graduated in Civil Engineering in the University of Rome "La Sapienza" and works as an engineer in Rete Ferroviaria Italiana (RFI), the Italian railways Infrastructure Manager. She is involved in railways lines capacity, studies and applications. She is member of 3 international Working Groups: Capacity WG in European Freight Corridor A Rotterdam-Genova, Capacity WG in European Freight Corridor D Valencia-Lyon-Torino-Ljubljana-Budapest and Capacity WG in European Freight Corridor B Hamburg-Napoli. She was member of European commission COST 337 and of World Road Association PIARC. She is author of more than 20 papers published on national reviews and national and international conference proceedings. Her e-mail address is $<p$. cicinierfi.it $>$.

FRANCESCO RONDINONE has been a stagiaire at RFI where he participated in the development of the work herein presented. He received a M.Sc. and a B.Sc. in Management Engineering from the University of Rome "Tor Vergata". His e-mail address is $<$ francesco. rondinonellibero.it>.

PAOLO DE LUCA is a consultant and expert in discrete event simulation. He currently operates for ACT Solutions - Analytics and Control Technology in several simulation projects. His activities and research interests concern the simulation and optimization of manufacturing and service systems. He received a M.Sc. and a B.Sc. in Management Engineering from the University of Rome "Tor Vergata". His e-mail address is <paolo. delucaeactsolutions.it>. 